\title{
Real-time Interactive Telemedicine for Ubiquitous Healthcare: Networks, Services and Scenarios
}

\author{
Georgi Graschew, Theo A. Roelofs \\ Stefan Rakow sky and Peter M. Schlag \\ Surgical Research Unit OP 2000, \\ Experimental and Clinical Research Center ECRC, \\ Max-Delbrück-Center for Molecular Medicine and \\ Charité - University Medicine Berlin, \\ Charité Campus Berlin-Buch, Lindenberger Weg 80, \\ D-13125 Berlin
}

Germany

\section{Introduction}

Ubiquitous access to high-level healthcare (u-Health) requires increasing use of Information and Communication Technology (ICT) solutions. Telemedicine describes the use of ICT for the delivery of medical services. It aims at equal access to medical expertise irrespective of the geographical location of the person in need. New developments in ICT have enabled the transmission of medical images in sufficiently high quality that allows for a reliable diagnosis to be determined by the expert at the receiving site (Pande et al., 2003; Lacroix et al., 2002). Through Telemedicine patients can get access to medical expertise that may not be available at the patients' site. Networks for Telemedicine enable the integration of distributed medical competence and contribute to the improvement of the quality of medical care, to the costeffective use of medical resources and to quick and reliable decisions.

For optimal performance of telemedical applications, the networks and communication tools used must be optimised for medical applications, both with respect to the Quality-of-Service (QoS, a set of parameters characterising the performance of the communication channel per se, such as transmission bandwidth, delay, jitter, data loss, etc.) as well as to the Class-ofService (CoS; a set of terms specifying the medical services offered in the network, like Telesurgery, Telepathology, Telesonography, Tele-Teaching, -Training \& -Education, etc.).

Using the specially-developed high-end interactive video communication system WinVicos for real-time interactive telemedical applications at a moderate transmission bandwidth of 0.5-1 Mbps OP 2000 has designed and implemented various satellite-based networks for telemedicine. To serve the specific requirements for management of disaster emergencies, the system developed in the framework of the DELTASS project provides logistic and telemedical services for disaster emergencies. OP 2000 has designed and validated various satellite-based interactive telemedical services that support the medical staff of a mobile field hospital within the disaster area by medical experts from a designated Reference 
Hospital outside of the disaster area. In MEDASHIP a system for telemedical support onboard of cruise ships and ferries has been set-up and evaluated. The EMISPHER project provides an equal access for most of the Euro-Mediterranean countries to online services for healthcare in expedient quality. Most of these services use WinVicos and combine high quality live video transmission with remote control of medical equipment.

The use of specifically designed networks for telemedicine contributes to the continuous improvement of patient care. Combined with the implementation of various enabling ICT tools to support distributed collaborative medical scenarios, such as high immersive visualisation, haptic feedback and stereoscopic and high-resolution visualisation, it can really contribute to the realisation of ubiquitous healthcare.

At the same time, however, these innovative developments in ICT bear the risk of creating and amplifying a digital divide in the world, creating a disparity in the quality of life, as this new ICT-based era leads to an increasingly dominant role of access to ICT resources in securing the quality of performance in many aspects of society (Graschew et al., 2003a; Dario et al., 2005; Graschew et al., 2004a). In recent years different projects have demonstrated how the digital divide is only one part of a more complex problem: the need for integration. (Wootton et al., 2005; Rheuban \& Sullivan, 2005; Graschew et al., 2003b; Graschew et al., 2002a).

In order to progress from e-Health and Telemedicine towards u-Health (i.e. ubiquitous access to high-level healthcare for everyone, anytime, anywhere) a real integration of both the various technology platforms (Quality of Service) and the various medical services (Class of Services) is needed. A virtual combination of interactive telemedical services to support medical telepresence serves as a basic concept for the development of Virtual Hospitals (VH). One key element within $\mathrm{VH}$ will be the medical workplace of the future, which is to provide each of the various user groups with tailored access to all relevant information at the right place and time and in an optimised form.

\section{Methodology}

During the last years OP 2000 (Operating Room of the future) has designed, developed and validated various modules for interactive telemedicine services (Schlag et al., 1999; Graschew et al., 2000). One of the key elements is the interactive telecommunication module WoTeSa / WinVicos: WoTeSa, a dedicated Workstation for Telemedical applications via Satellite that uses the communication software WinVicos (Wavelet-based interactive Video communication system).

WoTeSa is a PC with sufficient processing capacity ( $\geq 3 \mathrm{GHz}$ Pentium IV, $\geq 512 \mathrm{MB}$ RAM), one or more Osprey video capture boards (Osprey 100 or Osprey 500), a camera with composite and s-video outputs as live source (e. g. Canon VC-C4); a second camera as document camera for transmission of non-digital images; standard headset or microphone with small loudspeakers. The different video inputs of the Osprey video capture card can be used for direct connection to various medical video sources. WoTeSa thus serves quasi as a medical video hub. It is noteworthy that WoTeSa is a dedicated workstation and yet it can be realised with off-the-shelf components, thus making it readily available and at the same time very flexible and adaptive.

WinVicos is an all-software high-quality interactive video communication system, supplying real-time video, still-image and audio-transmission. WinVicos is especially designed for telemedical applications (e.g. telesurgery, teleradiology, telepathology) using a 
hybrid speed-optimised wavelet-codec that is based on the concepts of Partition, Aggregation and Conditional Coding (PACC; Patent DE 19734542 A1 from "Deutsche Telekom", Darmstadt, Germany). In contrast to most mainstream video coding systems that are mostly optimised for cinema and home entertainment, the PACC codec does not employ motion estimation but maximises the frame resolution to allow for maximal details to be visualised. WinVicos communicates IP-based and allows for online scaling of the transmission parameters (bit rate, frame rate and frame size from $128 \times 96$ up to $640 \times 480$ pixel). It supports both point-to-point and multipoint communication scenarios. Besides high quality live video transmission using moderate bandwidths $(0.5-1 \mathrm{Mbit} / \mathrm{s})$ it also allows for still-image transmission. WinVicos is very easy to use: there is a main user interface that is sufficient for the standard actions of the user. This includes calling the video conference partner via a telephone book, adjustment of both local and remote transmission parameters, as well as speaker and microphone volume control (see Fig. 1).

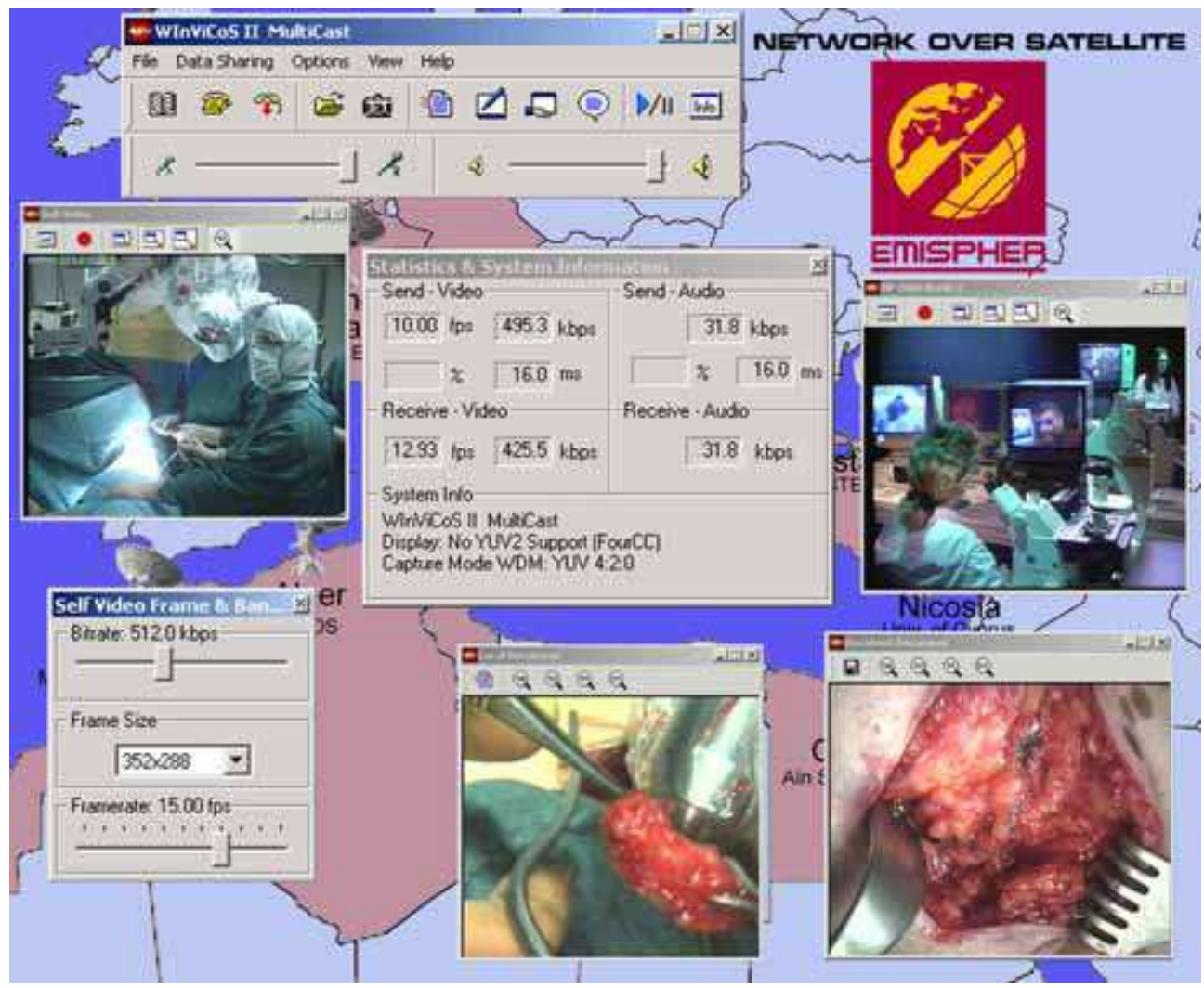

Fig. 1. WinVicos main user interface (top): two live video windows (top) and two still-image windows (bottom), online flexible adjustment of transmission parameters (bottom left), transmission performance can be monitored online (center).

In both the video windows and the still-image windows WinVicos supports the use of common cursors shared by the conference partners. As WinVicos is an all-software system 
not only the implementation of other video codecs can be readily realised, but also a continuous performance improvement is supported to keep up with recent developments in the field. The most recent version of WinVicos also supports the transmission of video streams in full high definition (HD) resolution.

Other telemedicine systems are used e.g. for tele-ultrasound in rural areas where telementoring by live videoconferencing allowed to guide the ultrasound technician to record additional images of the patient (O'Neill et al., 2000) for clinical assessment of pediatric burns which showed a good agreement between the face-to-face consultation and seeing the patient via videoconference (Smith et al., 2004) and for home telecare services likely to improve quality of health services (Guillen et al., 2002). Other systems are described in Sable 2002; Latifi et al., 2004; Eadie et al., 2003.

\section{Networks and services}

OP 2000 has been a prominent partner in various telemedical networks using satellite-based technology for the deployment of services for interactive video communication and medical telepresence (Graschew et al., 2009). In the following, three projects will be described in which WoTeSa / WinVicos have been used as interactive tool for real-time telemedical application services and e-learning scenarios.

\subsection{Disaster Emergency Logistic Telemedicine Advanced Satellites System - DELTASS}

The DELTASS Consortium consists of: Centre National D'Etudes Spatiales (F), MEDES (Institut de Médecine et de Physiologie Spatiales (F), SPACEBEL (B), Alcatel Space Industries (F), EADS - DORNIER (European Aeronautic Defence and Space Company (D), EADS - MS\&I (European Aeronautic Defence and Space Company - Matra Systémes \& Information (F), and Surgical Research Unit OP 2000 at Charité (D).

The DELTASS project was funded by the European Space Agency (ESA) as part of the ARTES-5 programme (Advanced Research in Telecommunications Systems).

Further general information on the DELTASS project can also be found at: http:/ / telecom.esa.int/ telecom/ www/ object/ index.cfm?fobjectid $=750$.

In the DELTASS-project (Graschew et al., 2008) a disaster scenario was analysed and an appropriate telecommunication system for effective rescue measures for the victims was set up and evaluated. Satellite-based systems are well suited for these circumstances, where generally ground infrastructures are partly or even totally destroyed. In such situations, even on a large geographic area or isolated area, space-based services can be easily and quickly deployed. DELTASS demonstrates operational performance of various services, covering the different aspects/phases of disaster emergency medicine. According to these phases, the DELTASS system is made up of the various corresponding subsystems (Fig. 2):

\section{Mobile Teams}

Mobile teams are deployed on the disaster site for search, identification, triage and evacuation of victims. They communicate with the coordination- and medical- teams located in Permanent Center or Mobile Field Hospital via low-rate (Globalstar, $9.6 \mathrm{kbps}$ ) and medium-rate (Inmarsat, $64 \mathrm{kbps}$ ) satellite telecommunication systems. Their positions are tracked via the established Global Positioning System (GPS satellite system). 


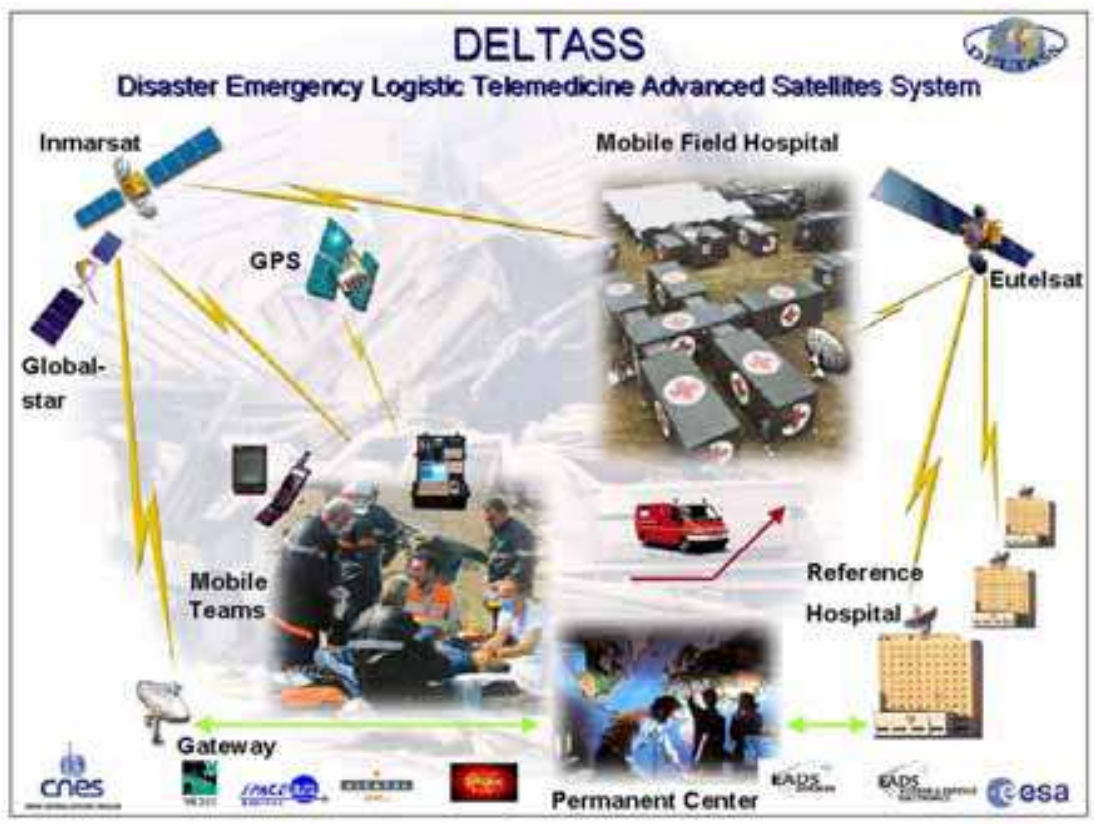

Fig. 2. DELTASS System Architecture: Mobile Teams, Permanent Center (PC), Mobile Field Hospital $(\mathrm{MFH})$ and Reference Hospital $(\mathrm{RH})$ are interconnected via several satellite systems with different bandwidths. Additionally terrestrial communication channels support the data exchange between the $\mathrm{PC}$ and the $\mathrm{RH}$.

\section{Permanent Center}

The Permanent Center is located outside the disaster area. The Permanent Center constitutes a new element in the architecture of support systems for disaster emergencies and is unique to the DELTASS system. In conventional set-ups the mobile teams at the disaster site are coordinated and supported by the staff of a Mobile Field Hospital deployed at or close to the disaster site. However, complete deployment of such a Mobile Field Hospital takes at least $\sim 6$ hours, usually $\sim 12$ hours, and consequently the activities of mobile teams in these first, highly critical hours, are ill-coordinated and far from optimal. To improve this bottleneck, DELTASS has a designated Permanent Center that is in control of coordination and medical support to the mobile teams from time zero on. The Permanent Center is equipped with terrestrial gateways to the Globalstar and Inmarsat satellite systems through which it receives all data from the mobile teams. It coordinates all actions of the mobile teams and manages all medical and logistic data, thus assuring efficient operation during the first critical phase. All data received at the Permanent Center are processed, appropriate Reference Hospitals (RH; see below) are identified and the logistic and medical data are transferred to these $\mathrm{RH}$ via terrestrial telecommunication links.

\section{Mobile Field Hospital (MFH)}

A Mobile Field Hospital (MFH), which will be deployed at or close to the disaster site, provides all activities related to the co-ordination of the mobile teams on the disaster site, the victims medical triage, reception, first aid treatment, conditioning for transportation, 
further medical expertise for some patients by teleconsultations between $\mathrm{MFH}$ and Reference Hospital(s).

\section{Reference Hospital (RH)}

The Reference Hospital(s) (RH), located outside of the disaster area, acts as an expert center by providing telemedical services to the MFH using the high-bandwidth satellite link (VSAT, $2 \mathrm{Mbps}$ ). These services consist of off-line and on-line telediagnosis, access to external medical databases, as well as real-time interactive telemedical services such as live teleconsultations, live telesonography, intraoperative virtual reality simulation and interactive telemicrobiology (see Fig. 3).

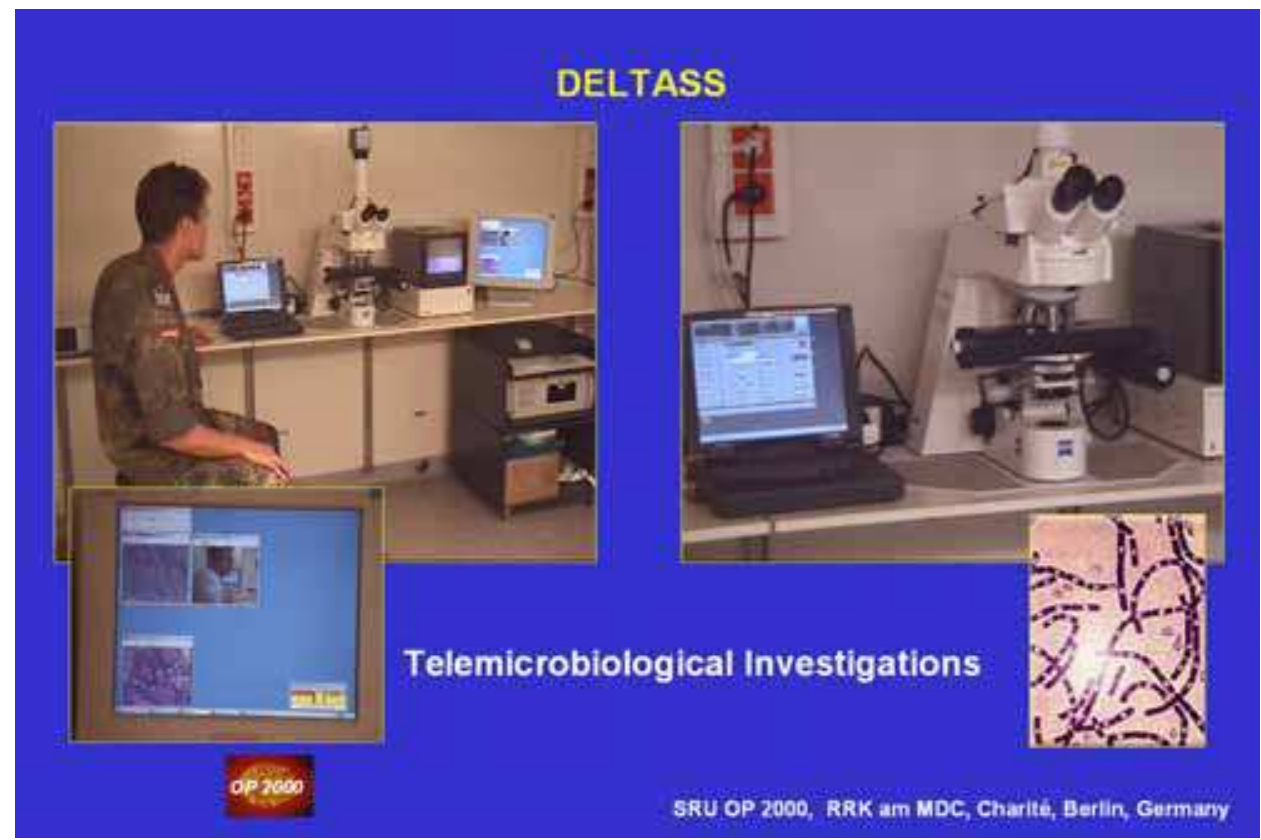

Fig. 3. Interactive Telemicrobiology: The microscope in the MFH can be completely controlled by an expert in the RH. The video data stream of the microscope camera is transmitted live to the RH using WoTeSa / WinVicos (insert left). In this way the expert in the RH can perform the investigation of the microbiological sample in the MFH (insert right) completely and interactively.

Statistics show that in cases of disaster emergency medicine, approx. $40 \%$ more amputations are performed, as compared to normal situation. One of the aims of providing live second opinion by remote experts is to reduce this number of unneeded amputations, manipulations and subsequent complications substantially, by expert support during triage, diagnosis and medical treatment.

These interactive telemedical services between the $\mathrm{MFH}$ and the $\mathrm{RH}$ are realised using the dedicated WoTeSa/ WinVicos system. WoTeSa/ WinVicos combines the user-friendliness and flexibility of IP-based communication protocols with the security and sufficiently-high quality of the live video transmission at a satellite bandwidth of only up to $2 \mathrm{Mbps}$. Medical experts at 
the $\mathrm{RH}$ support the medical treatments in the $\mathrm{MFH}$ and enable a quick and reliable decision concerning treatment and/ or evacuation of the patient/ victim. In this way, the quality of the provided medical service during and after disaster emergencies is strongly improved.

The performance of the DELTASS system has been shown during various full-size live demonstrations (http:/ / telecom.esa.int/ telecom/ www/ object/ index.cfm?fobjectid=6324).

\subsection{Medical Assistance for Ships - MEDASHIP}

Cooperating partners: D'Appolonia (I), AVIENDA (UK), Eutelsat (F), NCSR Demokritos (GR); co-funded by the European Union (EU) under the eTEN programme.

The main objective of the service developed by the MEDASHIP project is to supply integrated solutions for medical consultations on-board of ships (Graschew et al., 2004b). The satellite-based telemedicine services address both passenger ships and merchant vessels and are intended to provide passengers and crew members with an effective medical assistance in cases of emergency and in all those cases where the on board medical staff requires second opinion. During the validation phase the service was tested on board of three ships with the possibility to have it connected to three land medical centers (Fig. 4).

In addition to the standard medical equipment aboard the ships, two video cameras, an electrocardiograph (ECG) and an ultrasound (US) equipment are used. With this equipment the following telemedical services have been realised using satellite transmission at a bandwidth of $512 \mathrm{kbps}$ up to $1 \mathrm{Mbps}$ offering the required high quality of images and video transmission:

\section{Teleconsultation}

The live camera on-board of the ship can be used to transmit the image of the doctor who is leading the examination on-board of the ship or the image of the patient when being questioned by the land-based expert. It can also be used to show the land-based expert an injured part of the patient's body which he needs to see for his consultation. Thus a very realistic and effective live communication is possible.

\section{Electrocardiography}

The ECG system is connected to WoTeSa on board the ship and can be controlled by the physician from this workstation. Via application sharing software also the expert can control the ECG system from the land-based workstation. The main menu that includes all the functions of the ECG as well as the patient's ECG is transmitted to the expert. Thus the expert and the physician on board can jointly acquire and analyse the ECG report.

\section{Telesonography}

The S-video output of the US equipment is directly connected to the Osprey video capture board. Satellite transmission tests have shown that not only still images can be transferred but also live ultrasound investigations can be transmitted at 500-700 kbps (see Fig. 5).

With a document camera analogous patient data can be captured and digitised by WinVicos as a document. For example X-ray or CT-images can be captured from an illumination board and displayed locally and transmitted using this document camera function.

\section{Reduction of cost}

The costs for emergency interventions for removing a passenger from the ship and hospitalisation abroad are not to be undervalued. The removal of a passenger in the 


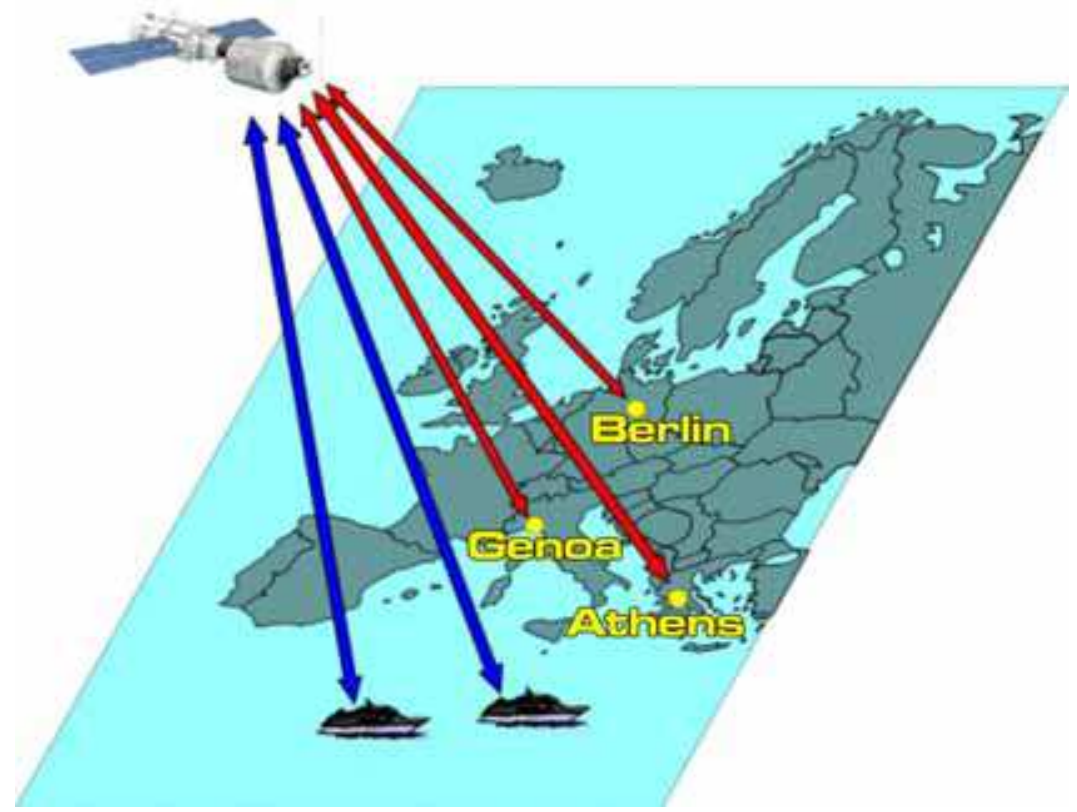

Fig. 4. MEDASHIP network connecting specially equipped ships in the Mediterranean Sea with three Reference Hospitals in Athens, Genoa and Berlin.

Carribean can cost up to $\$ 11.000$ and the cost for hospitalisation can range from $500-1000 €$ per day. Consequently, market trends force passenger shipping lines to offer services that help to improve the response to on-board clinical emergencies, improve the customer satisfaction and the companies' image.

\subsection{Euro-Mediterranean Internet-Satellite Platform for Health, medical Education and Research - EMISPHER}

In cooperation with: FMPC - Faculty of Medicine and Pharmacy of Casablanca, Morocco; ANDS - Agence National de Documentation de la Santé (Ministère de la Santé), Algiers, Algeria; Tunis - Faculty of Medicine of Tunis, Tunisia; ASU - Aïn Shams University, Cairo, Egypt; NIFRT - Nasser Institute for Research and Treatment (Ministry of Health and Population, MOHP), Cairo, Egypt; UCY - University of Cyprus, Nicosia, Cyprus; ISTEM Continuing Medical Education and Research Center, University of Istanbul, Turkey; NCSR Demokritos, Athens, Greece; IsMeTT - Istituto Mediterraneo per i Trapianti e Terapie ad Alta Specializzazione, Palermo, Italy; CICE - Centre International de Chirurgie Endoscopique, Clermont-Ferrand, France; and Charité University Medicine Berlin, Germany; co-funded by the European Union (EU) under the EUMEDIS / MEDA programme.

EMISPHER is dedicated to establish an equal access for most of the countries of the EuroMediterranean area to real-time and on-line services for healthcare in the required quality of service (see www.emispher.org). In the project an integrated Internet-Satellite platform has been set up on which three main areas of work have been realised: Virtual Medical University, Real-Time Telemedicine, and Medical Assistance (Graschew et al., 2005a). The 


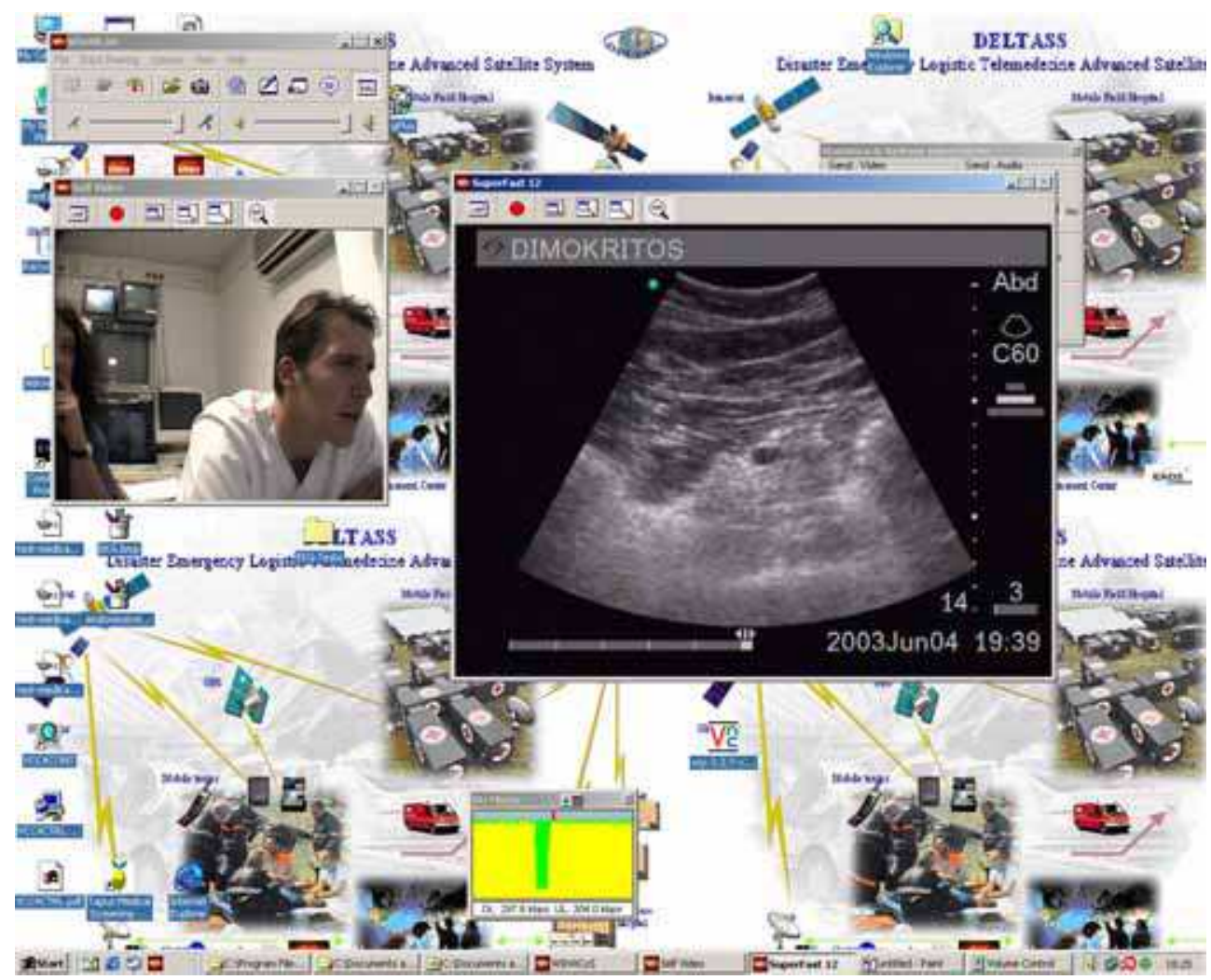

Fig. 5. Telesonography: Tehe live signals of the ultrasound equipment on-board of the ship are transmitted to the reference hospital. A physician at Charité is consulting the ultrasound examination of a patient on board of the cruise ship.

platform includes a bi-directional satellite network (up to $2 \mathrm{Mbps}$ ) between 10 Centers of Excellence in the Euro-Mediterranean region (Morocco, Algeria, Tunisia, Egypt, Cyprus, Turkey, Greece, Italy, France and Germany; see Fig. 6). For dissemination of the achieved results and for maximising its impact, EMISPHER has organised international conferences at each of the Mediterranean partner sites.

\section{The EMISPHER Virtual Medical University}

The formation and operation of the EMISPHER Virtual Medical University (EVMU) for elearning (teleteaching) is one of the main efforts in the project. The EVMU uses real-time broadcast of lectures, live surgical operations and pre-recorded video sequences etc., as well as web-based e-learning applications. The target population of the EVMU is comprised of medical students (both undergraduate and postgraduate) hospital staff, general practitioners and specialists, health officers and citizens.

Each of the leading medical centers provides didactical material and modules for synchronous and asynchronous e-learning in their medical specialties. The central gateway to EVMU is the project's website: www.emispher.org. 


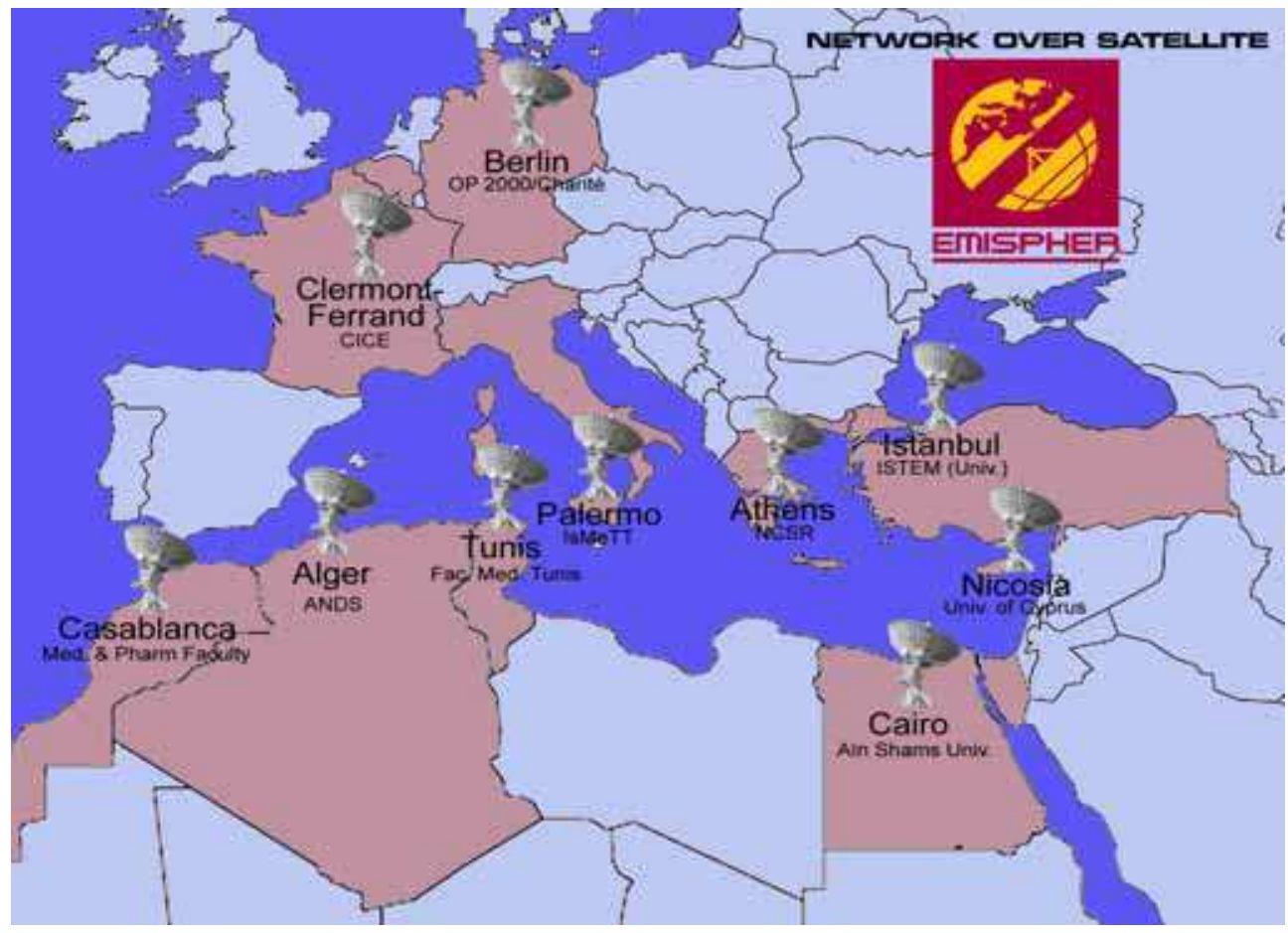

Fig. 6. Medical Centers in the EMISPHER Network

Some of the multimedia teaching material needs to be presented in real-time. Live transmission of surgical operations from operating theatres, lectures, etc. from one site to one or several sites simultaneously (point-to-point or multipoint) are possible in the network between the 10 partners.

\section{Real-Time Telemedicine}

EMISPHER has set up a satellite-based network using the combined WoTeSa and WinVicos modules for real-time telemedicine. In the field of real-time telemedicine the following categories of applications are offered: second opinion (Fig. 7), teleteaching \& teletraining (demonstration and spread of new techniques), telementoring (enhancement of staff qualification), and undergraduate teaching courses and optimisation of the learning curve. The leading medical centers in the project provide expertise in the following medical fields: open and minimally-invasive surgery, multi-organ transplantation, endoscopy, pathology, radiology, interventional imaging, neurology, infectious diseases, oncology, gynaecology and obstetrics, reproductive medicine, etc. These real-time telemedical applications contribute to improved quality of patient care and to accelerated qualification of medical doctors in their respective specialty. The main target audience are specialist doctors.

\section{Medical Assistance}

The third field of service operated in EMISPHER is medical assistance. As tourism constitutes a substantial economical factor in the Mediterranean region and because of the increasing mobility of the population, continuity of care through improved medical 


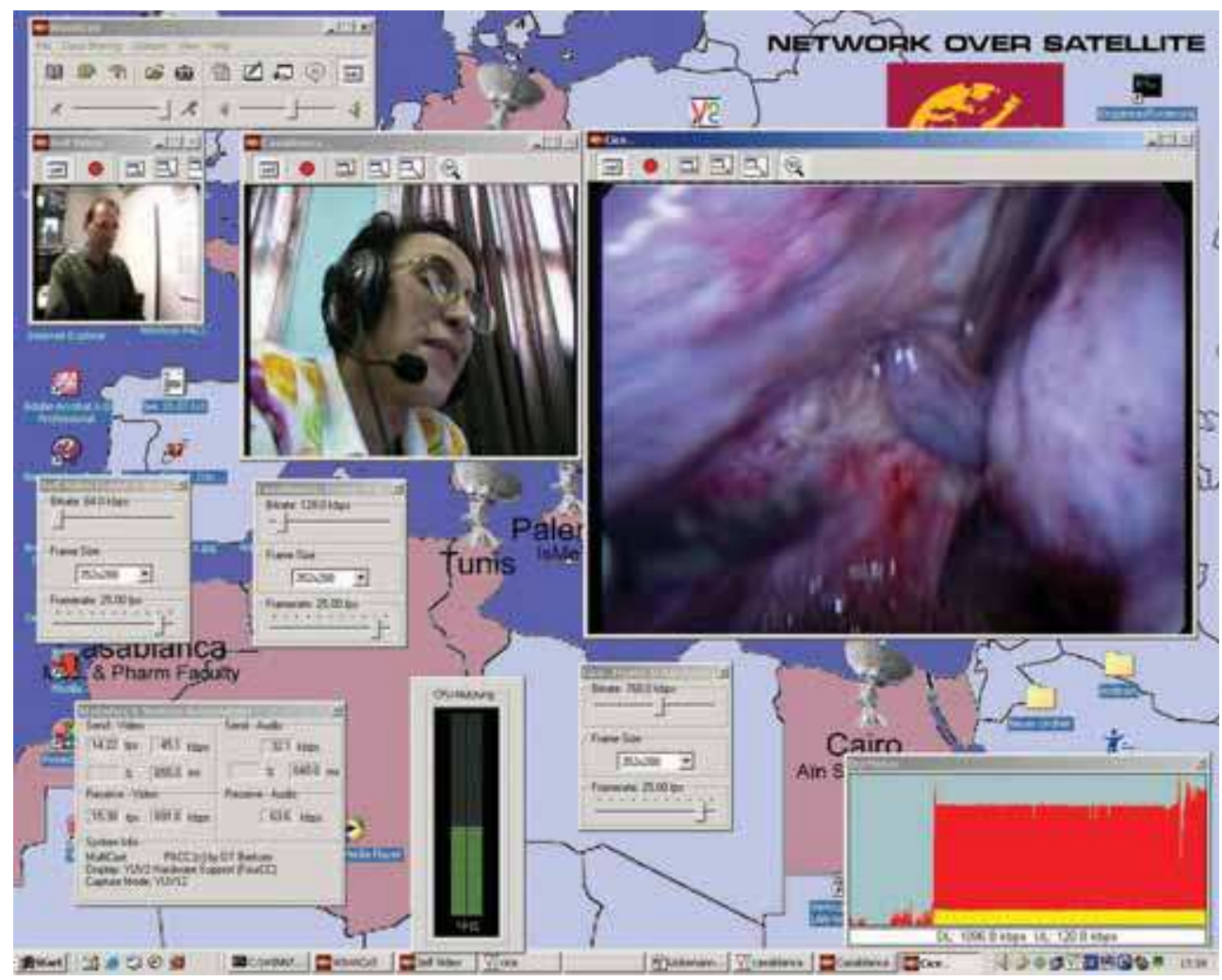

Fig. 7. Interactive multipoint teleconsultation during laparoscopy betw een OP 2000 (Berlin), Faculté de Médecine et de Pharmacie (FMPC, Casablanca) and Centre International de Chirurgie Endoscopique (CICE, France)

assistance is of major importance for improved healthcare in the Euro-Mediterranean region. Introduction of standardised procedures, integration of the platform with the various local communication systems and training of the medical and non-medical staff involved in the medical assistance chain allow for shared management of files related to medical assistance (medical images, diagnosis, workflow, financial management, etc.) and thus for improved care for travellers and expatriates.

\section{Advanced scenarios for ubiquitous healthcare}

Besides the implementation of telemedicine networks and services OP 2000 also designs, and develops modules for the operating room of the future by combined use of computer-, video-, communication- and laser technology in the clinical routine of surgery and surgical oncology. Its goal is to achieve more precise, optimised tumour diagnosis and therapy.

OP 2000 is a concept for the operating room of the future by the combined application of computer-, video- and communication-technology in the clinical routine. Its goal is to optimise user interfaces for intraoperative tasks and to introduce virtual reality simulation, haptic feedback, stereoscopic visualisation and interactive real-time video communication to 
support telemanipulation, teletraining and telementoring, thus achieving more precise, optimised and personalised tumour diagnosis and therapy.

In medicine the acquisition, processing and display of medical data is gaining more and more importance with increasing processing capacity. The advantages of the computerassisted simulation of surgical procedures in a high-immersive, distributed, virtual environment are that one can gain a precise and intuitive image of an individual organ for diagnostic purposes or operation planning. The more senses are addressed by the display the quicker, more intuitive and more exact details are conveyed to the medical doctor. One approach is the implementation of a haptic device to enable to feel the shape and surface structure of the organ with simultaneous stereoscopic visualisation and tracking of the user. For patient-specific pre-operative planning stereoscopic high-resolution imaging and collaboration are important (Montgomery, 2005). The use of a virtual reality environment e.g. for pre-operative planning of total hip replacement yields a high accuracy and steep learning curve even for first-time users (Testi, 2006).

Different haptic feedback systems have been applied and evaluated for the training of open surgery (Hu, 2006), minimally-invasive procedures or colonoscopy (Hellier, 2008), neurosurgery (Lemole, 2007), cataract eye surgery (Doyle, 2008). Virtual reality simulators need haptic devices with force feedback capability if tissue consistency information is to be delivered (Lamata, 2006).

\subsection{High immersive workbench projection: the surgical table}

On the basis of the distributed environment of a cooperative medical workbench (Fröhlich, 1995) a high immersive virtual environment called Surgical Table has been developed, specially designed for the simulation and training of surgical interventions (Graschew et al., 2002b).

Briefly: a surgeon supervises a surgical training of one of his medical students. Therefore a three-dimensional reconstruction of radiological patient data is being projected onto the workbench. The student manipulates the model, rotates and moves it on the workbench. $\mathrm{He}$ may touch bones or cut through some skin or tissue with a virtual tool. While doing so he watches his actions in $3 \mathrm{D}$ and feels matching haptic sensations. At the same time the surgeon is able to observe his student's actions and he can give guidance as he is able to point at structures (e.g. a tumour), to talk to the student or to demonstrate an intervention (telementoring). During such a training session it is also possible to have virtual windows showing additional information, movies, or video conferences with other experts or participants. The Surgical Table consists of two high-resolution HDTV-projectors (1600x1200 pixels) integrated in a mobile unit, where virtual objects and control tools are projected on a real workbench (Fig. 8). Collaborative simulations for two users positioned on opposite sides of the Surgical Table are possible, as is the case during real surgery.

The projective display system frees the user from the heavy load and inconvenience related to head mounted displays and enables virtual reality for routine applications. Due to the combined application of two HDTV-projectors, polarisation technique and shutter glasses the Surgical Table allows for several working modes:

\section{- Double-tracked mode:}

Simultaneous projection (in broadcast quality) of two different stereoscopic views of a virtual scenario by combination of shutter and linear polarisation techniques. Both users are individually tracked with the electromagnetic multi-channel Polhemus Fastrak sytem (sensors on the glasses and the stylus) and wear polarised glasses that 
only allow visibility of their corresponding projector. For stereoscopic imaging active shutter glasses are used. Both users can work on the common data set, each using their own toolbar. In this mode, collaborative simulations for two users positioned on opposite sides of the surgical table are possible, as is the situation during real surgery (see Fig. 9).

- Double mode:

This mode enables two users to work simultaneously on the Surgical Table, each on their distinct data set. Each user has an additional monitor for medical second opinioning.

- $\quad$ Stereoscopic HDTV-mode:

Projection of stereoscopic, full resolution HDTV. Sources for the displayed scenarios are computer-generated, three-dimensional models, computer-based movies, as well live pictures from stereoscopic HDTV cameras. In the SRU OP2000 these are various 3D HDTV camera systems available: 3D HDTV camera for open surgery, a 3D HDTV surgical microscope and a HDTV pathological microscope.

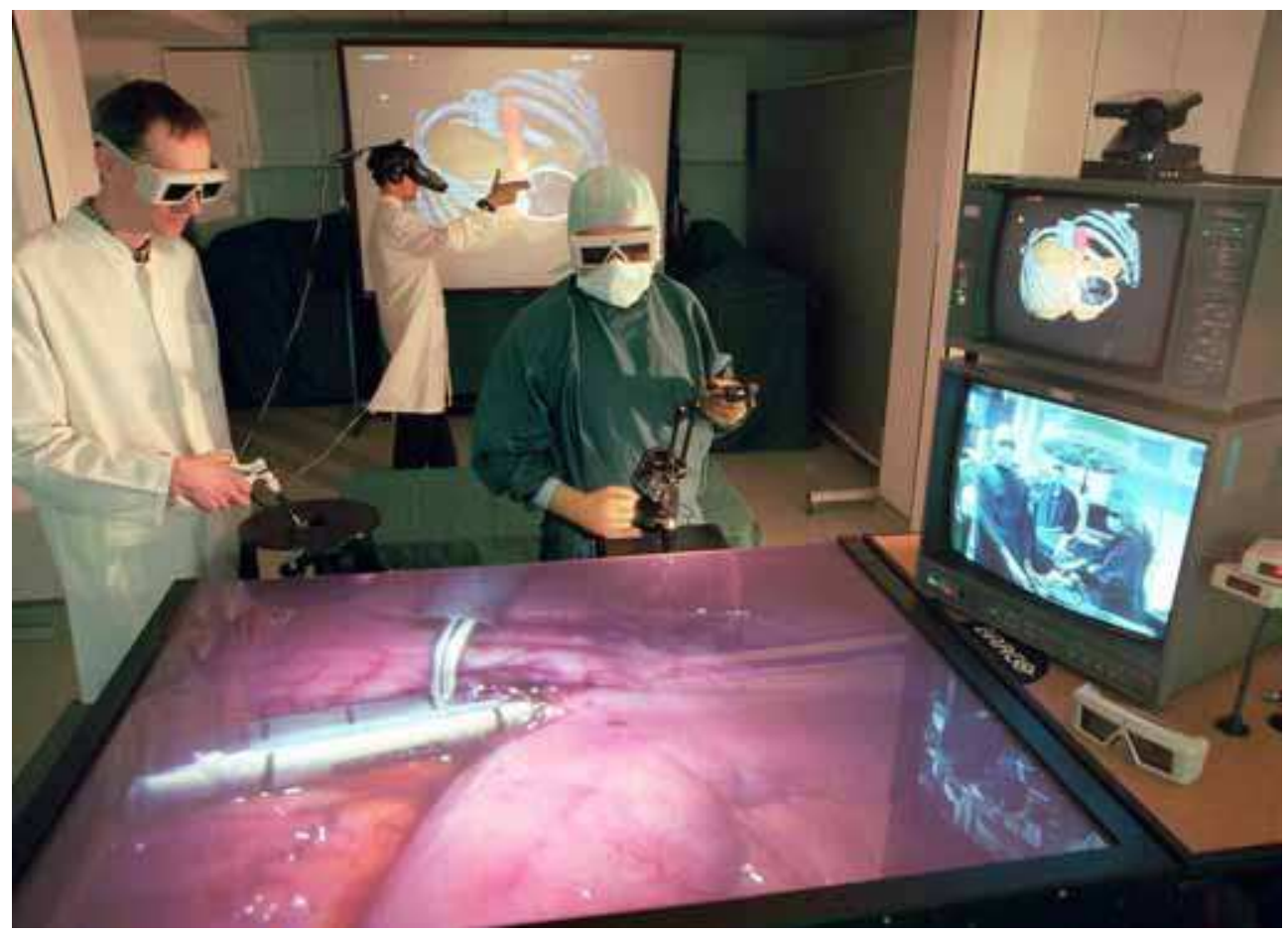

Fig. 8. Realistic simulations of surgical procedures 


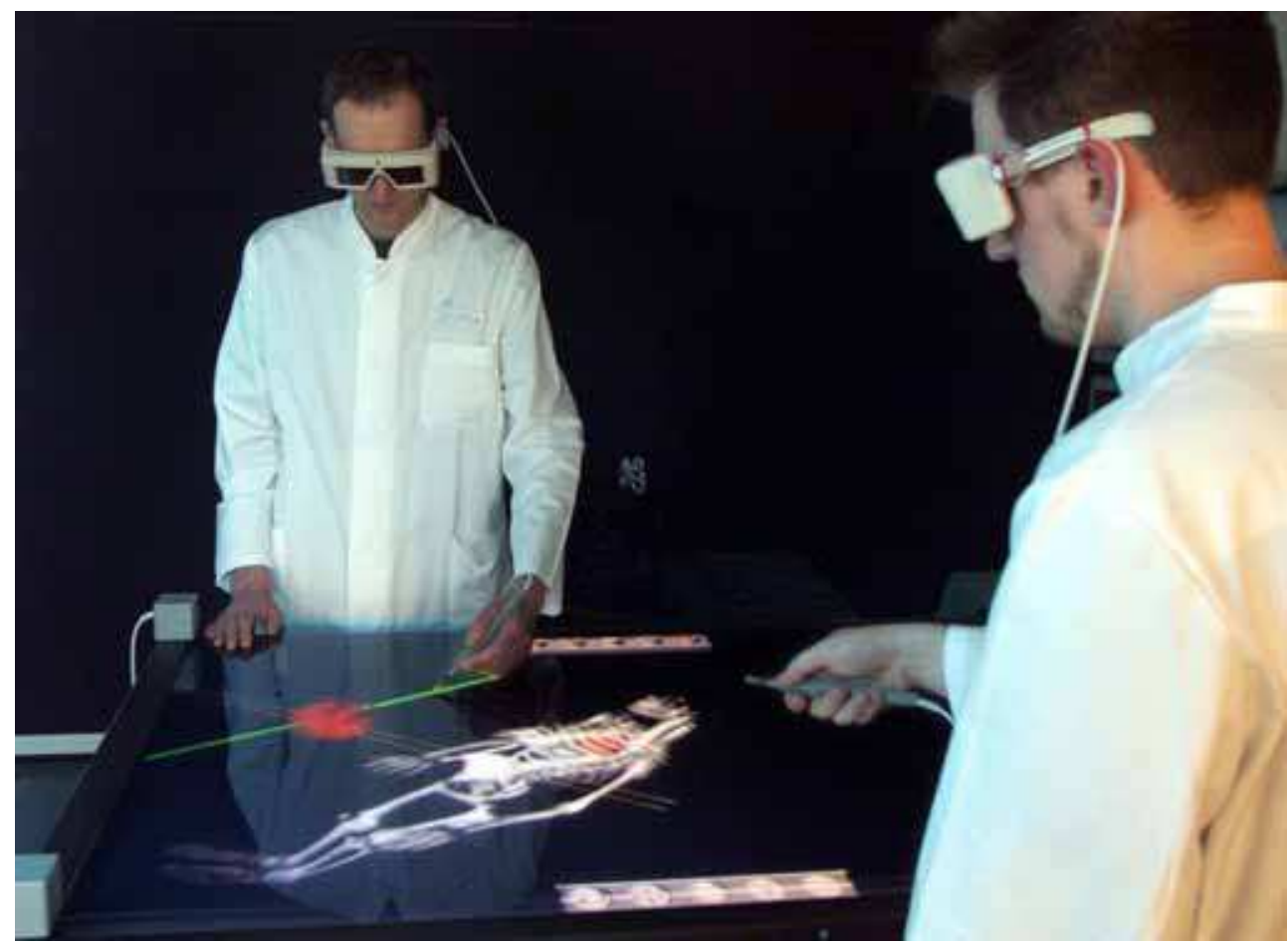

Fig. 9. Surgical Table: Simultaneous display of two opposite tracked views of the same data set (double-tracked mode)

\subsection{Haptic feedback}

Haptic feedback for touching and navigation of virtual objects with simultaneous stereoscopic visualisation in a distributed network environment has been implemented (Graschew, 2005b). This allows multiple users to feel the shape and surface structure of an organ with simultaneous stereoscopic visualisation and tracking of the user for surgical training.

Client-server architecture allows for distributed usage of the simulation. The server manages the 3-D scene graph by VRML loading and Java-3D scene graph building. Changing of the scene graph by a client is enabled by the synchronisation of the 3-D data. This architecture allows for navigation through the environment by each client. The task of making the objects touchable is achieved by the integration of the PHANTOM haptic device, a high precision 3-D force-feedback system for touching and manipulating the virtual objects (see Fig. 10). The schematic setup for a client with haptic integration is depicted in Fig. 11. The 3-D data are transferred and mapped to the haptic device. The simulation utilises the dynamic data from the PHANTOM haptic device.

A 3-D graphic card and a monitor with an active LCD-shutter in combination with polarising glasses allow the stereoscopic display of selected 3-D objects (e.g. spinal cord, brain, heart, etc.). The head movements of the user are tracked by an IR-tracking system enabling a visualisation of the object with the correct perspective according to the actual 


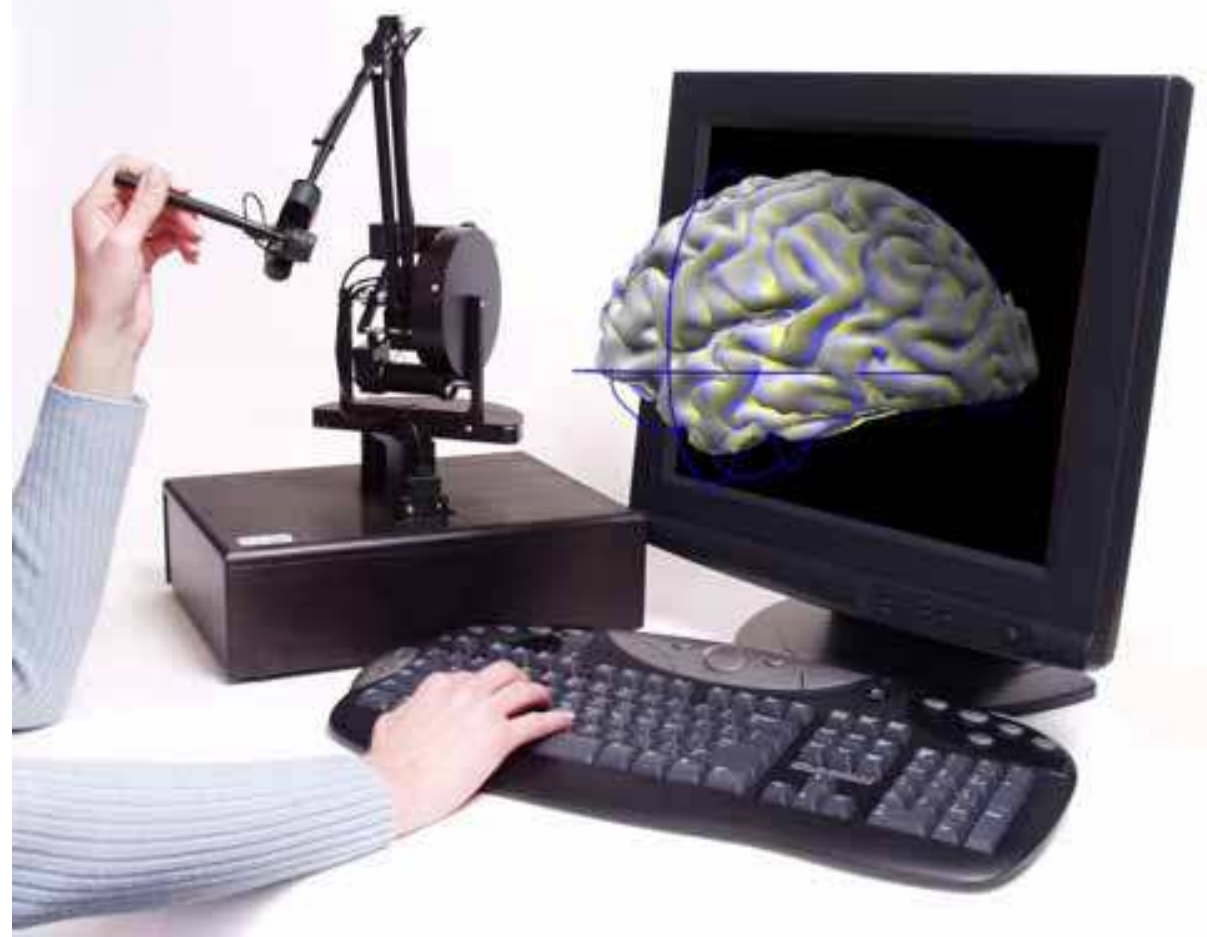

Fig. 10. Phantom haptic device

position of the user. With the PHANTOM haptic device it is possible to rotate and translate the object. Also with the PHANTOM it is possible to navigate a small pointer on the screen around the object and feel the surface structure at the tip of the pointer. Through natural access pathways it is also possible to navigate inside the object.

\subsection{Stereoscopic and high-definition visualisation}

Stereoscopic visualisation has been realised to achieve a better spatial coordination for the surgeon where he has to rely on video images instead of on his direct sight. As medical stereoscopic video sources a $3 \mathrm{D}$ camera integrated into the operating light is used to transmit images from the site of operation in open surgery. A 3D surgical microscope can visualise structures as small as 50 micrometers and gives the surgeon a magnified view e. $\mathrm{g}$. in vascular surgery. For minimally invasive surgery a 3D laparoscope gives the surgeon a stereoscopic view inside the body of the patient.

High quality and high definition cameras have been adapted to different medical imaging devices and tested for medical purposes. For example a single definition 3-chip-CCD camera and an HDTV camera have been compared in a microscope for telepathology revealing greater details in the HD image of a pathological slide. Also a stereoscopic surgical microscope has been equipped with a pair of high definition 3-chip-CCD cameras with a special HDTV optical adapter yielding a higher contrast image. The use of HD-video systems in endoscopic and laparoscopic surgery leads to improved surgical dexterity 


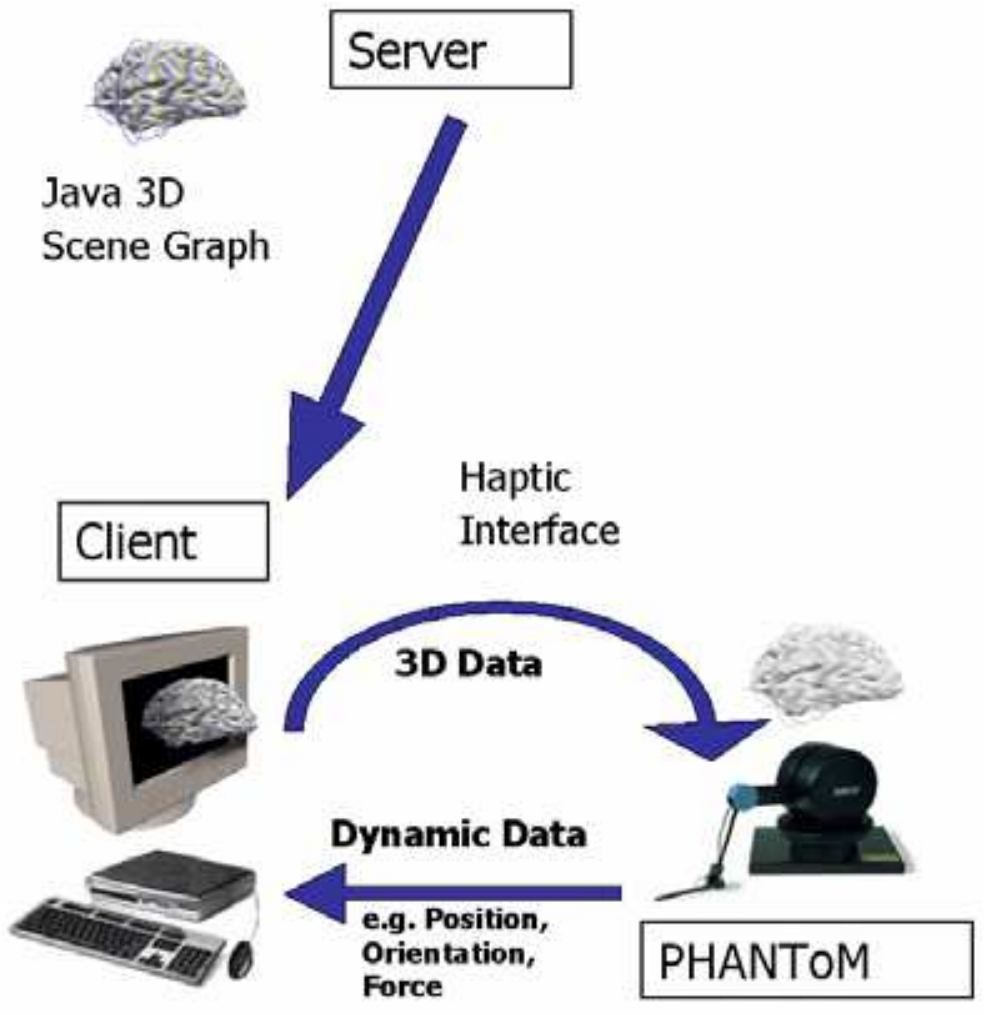

Fig. 11. Client with haptic integration

compared to 3-chip-CCD video systems as the surgeon has to visually judge tissue alterations, van Bergen 2000; Hagiike 2007).

Applying more and more effective compression techniques real-time transmission of stereoscopic medical video also live from the operating room using less bandwidth has become available. The real time transmission of uncompressed medical HD video would require a bandwidth of approximately $1000 \mathrm{Mbit} / \mathrm{s}$. For the clinic-external transmission via existing networks a compression of the video data is required. The implementation of a codec for the coding of medical video data with HD resolution is in preparation.

The requirements for stereoscopic and HD video transmission are met by the WoTeSa/ WinVicos communication system (see section 2).

\section{Conclusions and perspectives: virtual hospitals and the medical workplace of the future}

Telemedicine networks and services are crucial to support ubiquitous access to healthcare. Appropriate enabling technologies must be deployed and interconnected via networks with an appropriate design. In this chapter we have presented WoTeSa/ WinVicos as a flexible high-end module for real-time interactive telemedical services. Besides video communication in medically expedient quality, the provision of interactivity for the remote 
control of medical equipment is indispensable. Both video communication and interactivity require a (nearly) real-time mode of bi-directional interactions. Various examples have been given of particular networks and services that have been deployed, each to support medical telepresence in specific functional scenarios (DELTASS MEDASHIP and EMISPHER).

However, despite substantial improvements that have been realised, these developments bear the risk of creating and amplifying digital divides in the world. To avoid and counteract this risk and to fulfil the promise of Telemedicine, namely ubiquitous access to high-level healthcare for everyone, anytime, anywhere (so-called ubiquitous Healthcare or $\mathrm{u}$-Health) a real integration of both the various platforms (providing the "Quality-ofService", QoS) and the various services (providing the "Class-of-Service", CoS) is required (Graschew et al., 2002; Graschew et al., 2003b; Wootton et al., 2005; Rheuban \& Sullivan 2005; Graschew et al., 2006a). A virtual combination of applications serves as the basic concept for the virtualisation of hospitals. Virtualisation of hospitals supports the creation of ubiquitous organisations for healthcare, which amplify the attributes of physical organisations by extending its power and reach. Instead of people having to come to the physical hospital for information and services the virtual hospital comes to them whenever they need it. The creation of Virtual Hospitals (VH) can bring us closer to the ultimate target of u-Health (Graschew et al., 2006b).

The methodologies of $\mathrm{VH}$ should be medical-needs-driven, rather than technology-driven. Moreover, they should also supply new management tools for virtual medical communities (e.g. to support trust-building in virtual communities). VH provide a modular architecture for integration of different telemedical solutions in one platform (see Fig. 12).

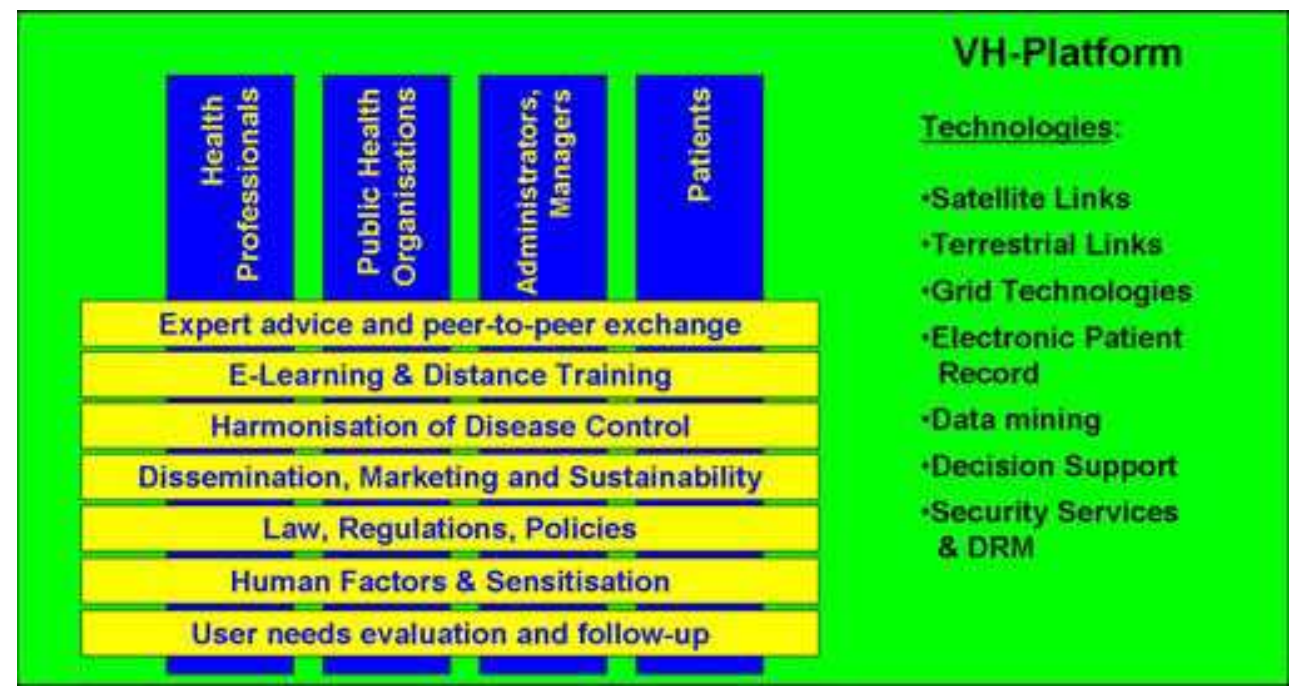

Fig. 12. Concept for the functional organisation of Virtual Hospitals (VH): The technologies of VH (providing the "Quality-of-Service", QoS) like satellite-terrestrial links, Grid technologies, etc. will be implemented as a transparent layer, so that the various user groups can access a variety of services (providing the "Class-of-Service", CoS) such as expert advice, e-learning, etc. on top of it, not bothering with the technological details and constraints. 
The technology supporting this platform (in Fig. 12 represented as a green basic layer) should be implemented as a transparent layer, so that the end-users do not need to bother with technological details and constraints. These technologies will include both satellite and terrestrial communication links with seamless transitions between the various segments. Due to the distributed character of $\mathrm{VH}$, data, computing resources as well as the need for these are distributed over many sites. Therefore, Grid infrastructures and services become useful for successful deployment of services like acquisition and processing of medical images (3D patient models), data storage, archiving and retrieval (especially for evidencebased medicine) [27]. Also generic technology tools like electronic patient records and data mining \& decision support systems have to be included, as well as tools for security services and data privacy \& ownership management. It is also obvious that the population of endusers (in Fig. 12 represented as blue columns) will quite heterogeneous and will include different categories such as health professionals, administrators and managers, public health organisations, as well as patients and citizens. Each of these groups must get tailored access to the various services to be provided. These services (in Fig. 12 represented as yellow rows) not only include the "classical" (tele-) medical services like consultation and exchange, education and training, etc., but must also address other key factors that are essential for successful realisation of u-Health: dissemination and marketing (to expand the number of stakeholders), sustainability (both in an economic and a social sense), law, regulations \& policies (for liability and reimbursement issues), human factors \& technology sensitisation (trust-building in virtual communities, technology acceptance, change management). Finally, it seems crucial for long-term success of $\mathrm{VH}$ in daily routine to apply rigorous users' needs evaluations in a continuous and iterative manner.

Due to the distributed character of $\mathrm{VH}$, data, computing resources as well as the need for these are distributed over many sites in the Virtual Hospital. Therefore, Grid infrastructures and services become useful for successful deployment of services like acquisition and processing of medical images (3D patient models), data storage, archiving and retrieval, as well as data mining, especially for evidence-based medicine (Graschew et al., 2006c).

One key element within $\mathrm{VH}$ will be the design, implementation, validation and optimisation of the medical workplace of the future (Project 2020) that shall integrate the various clinically required modalities into one integrated workplace that will provide each of the various user groups with tailored access to all relevant information at the right place and time and in an optimised form.

The project 2020 represents trend-setting tele-medical technology by the use of a high-tech system configuration on the basis of linked application-specific modules. The individual modules are spatially and functionally autonomous units carrying out the primary data acquisition and processing. The image recording and processing modules along with the communication equipment enable the display of all visual information in real-time (3-D video conference). This equipment and functional modules can be operated via a standardised, surgical user environment. The modules are linked to form a universal configuration (user environment peripheral operation, monitoring facilities, 3-D image display; see Fig. 13).

The further design, implementation, validation and optimisation of a surgical-oncological workplace 2020 in which the various clinically required modalities are to be integrated is an important component for peri-operative research. This medical workplace 2020 shall provide the users with all required information at the right time and place and most important in optimally processed form. Important for a workplace 2020 is an integration of 
the following aspects: high-resolution (HD) and stereoscopic visualisation; interactive realtime video communication with remote control of medical devices for tele-mentoring, teletraining and distributed collaborative work; virtual reality simulations with tracked visualisation and haptic feedback; optimised user interfaces for intraoperative use, etc. By a modular design of the workplace 2020 the various functional groups in the daily clinical routine gain a tailored access to all required medical information, video communication, simulation, etc. The corresponding application of modern technologies of interaction as well as the extensive integration of the various modalities contributes to a more efficient and effective tele-mentoring and tele-training and finally the dissemination of new treatment methods and concepts.

Finally, the possibility to get support from external experts, the improvement of the precision of the medical treatment by means of a real medical telepresence, as well as online documentation and hence improved analysis of the available data of a patient, all contribute to an improvement in treatment and care of patients in all circumstances, thus supporting our progress from e-Health and Telemedicine tow ards real u-Health.

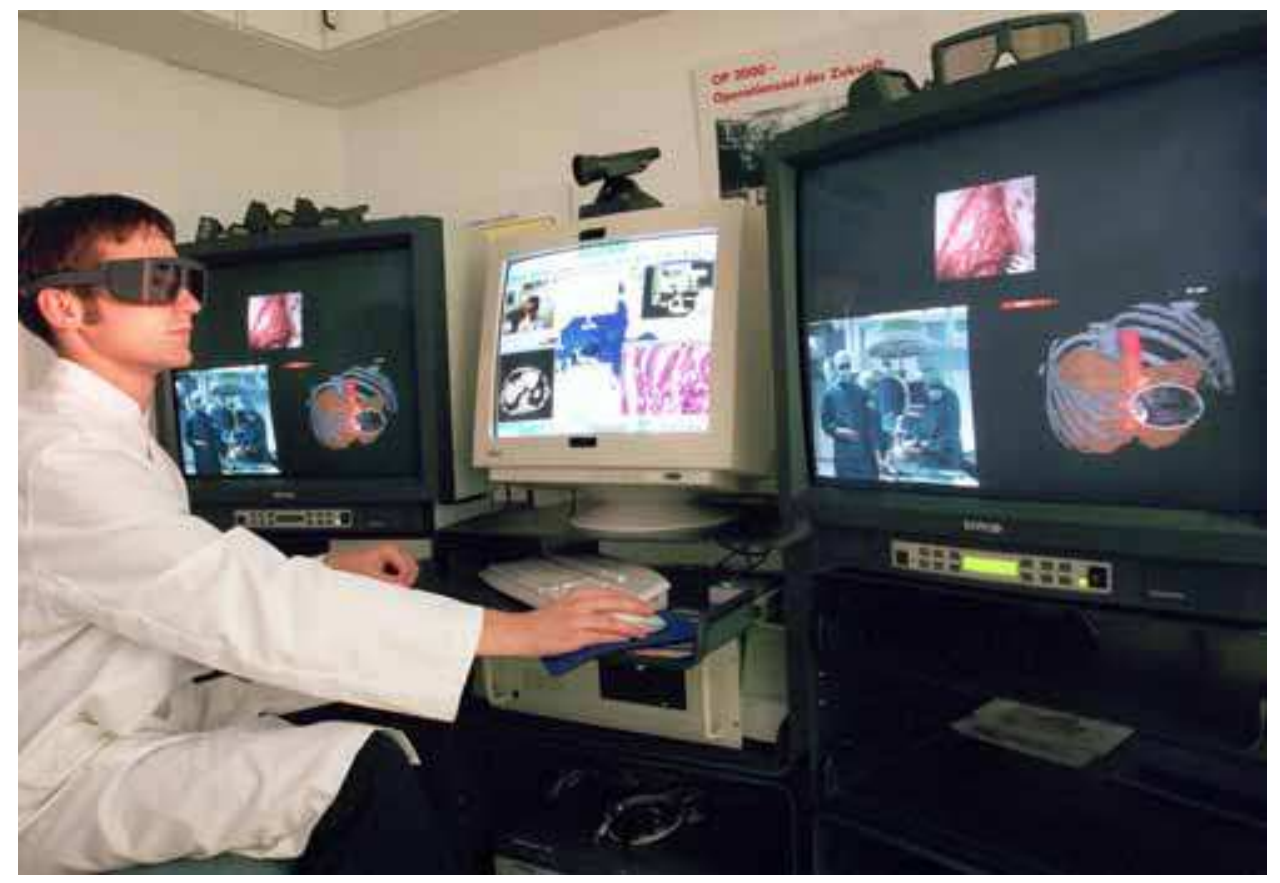

Fig. 13. Workplace 2020 for Surgical Oncology: Stereoscopic visualisation and real-time interactive video communication

\section{References}

Dario, C. et al. (2005). Opportunities and Challenges of eHealth and Telemedicine via Satellite. Eur II Med. Res., Vol. 10, Suppl I, Proceedings of ESRIN-Symposium, duly 5, 2004, Frascati, Italy, (2005), pp. 1-52. 
Doyle L., et al., (2008). A simulator to explore the role of haptic feedback in cataract surgery training. Stud Health Technol Inform. Vol. 132, pp. 106-111.

Eadie, L.H. et al., (2003). Telemedicine in surgery. Br. el Surg., Vol. 90, pp. 647-58.

Fröhlich B. et al., (1995). The Responsive Workbench: A Virtual Working Environment for Physicians. Comput. Biol. Med. Vol. 25, pp. 301-308.

Graschew, G. et al. (2000). Interactive telemedicine in the operating theatre of the future. $J$ Telemedicine and Telecare Vol. 6, Suppl. 2, pp. 20-24.

Graschew, G. et al. (2002a). Broadband Networks for Interactive Telemedical Applications, APOC 2002, Applications of Broadband Optical and Wireless Networks, Shanghai 16.17.10.2002, Proceedings of SPIE, Vol. 4912, pp. 1-6.

Graschew G., et al., (2002b). High immersive Visualisation and Simulation in the OP 2000 Operating Room of the Future. Proceedings of the 5th IASTED Conference, Computer Graphics and Imaging p.266-268.

Graschew, G. et al. (2003a). Telemedicine as a Bridge to Avoid the Digital Divide World, 8. Fortbildungsveranstaltung und Arbeitstagung Telemed 2003, Berlin, 7.-8. November 2003, Tagungsband, pp. 122-127.

Graschew, G. et al. (2003b). Telepresence over Satellite, Proceedings of the 17th International Congress Computer Assisted Radiology and Surgery, London, 25.-28.6.2003, International Congress Series, Vol. 1256, ed. H.U. Lemke et al., pp. 273-278.

Graschew, G. et al. (2004a). Interactive Telemedicine as a Tool to Avoid a Digital Divide of the World, In: Medical Care and Compunetics 1, L. Bos (Ed.), pp. 150-156, IOS Press, Amsterdam.

Graschew, G. et al., (2004b). MEDASHIP - Medizinische Assistenz an Bord von Schiffen, In: Telemedizinfuihrer Deutschland, ed. 2004, A. Jäckel (Ed.), Deutsches Medizin Forum, Ober-Mörlen, Germany, pp. 45-50.

Graschew, G. et al., (2005a). Überbrückung der digitalen Teilung in der Euro-Mediterranen Gesundheitsversorgung - das EMISPHER-Projekt, In: Telemedizinfuihrer Deutschland, ed. 2005, A. Jäckel (Ed.), Ober-Mörlen, Germany, pp. 231-236.

Graschew G. et al., (2005b). Java-3D Based Virtual Environment for Teaching and Training. Proceedings of the 13th International Congress of the European Association for Endoscopic Surgery - EAES, p. 125.

Graschew, G. et al., (2006a). VEMH - Virtual Euro-Mediterranean Hospital für Evidenzbasierte Medizin in der Euro-Mediterranen Region, In: Telemedizinführer Deutschland, Ausgabe 2006, A. Jäckel (Ed.), Medizin Forum AG, Bad Nauheim, Germany, pp. 233-236.

Graschew, G. et al., (2006b). New Trends in the Virtualization of Hospitals - Tools for Global e-Health, In: Medical and Care Compunetics 3, L. Bos et al. (Eds.) Proceedings of ICMCC 2006, The Hague, 7-9 June 2006, IOS Press, Amsterdam, pp.168-175.

Graschew, G. et al., (2006c). Virtual Hospital and Digital Medicine - Why is the GRD needed?, In: Challenges and Opportunities of HealthGrids, V. Hernandez et al. (Eds.) Proceedings of HealthGrid 2006, Valencia, 7-9 June 2006, IOS Press, Amsterdam, pp.295-304. 
Graschew, G. et al., (2008). DELTASS - Disaster Emergency Logistic Telemedicine Advanced Satellites System - Telemedical Services for Disaster Emergencies. International cburnal of Risk Assessment and Management Vol. 9, pp. 351-366.

Graschew, G. et al., (2009). New developments in network design for telemedicine. Hospital IT Europe, Vol. 2 No. 2, pp. 15-18.

Guillen, S. et al., (2002). User satisfaction with home telecare based on broadband communication. el Telemed. Telecare, Vol. 8, pp. 81-90.

Hagiike M. et al., (2007). Performance differences in laparoscopic surgical skills between true high-definition and three-chip CCD video systems. Surg Endosc. Vol. 21, pp. 1849-1854.

Hellier D. et al., (2008). A modular simulation framework for colonoscopy using a new haptic device. Stud Health Technol Inform. Vol. 132, pp. 165-170.

$\mathrm{Hu}$ J., et al., (2006). Effectiveness of haptic feedback in open surgery simulation and training systems. Stud Health Technol Inform. Vol. 119, pp. 213-218.

Lacroix, L. et al., (2002). International concerted action on collaboration in telemedicine: recommendations of the G-8 Global Healthcare Applications Subproject-4. Telemed. I E-Health, Vol. 8, pp. 149-157.

Lamata P. et al., (2006). Tissue consistency perception in laparoscopy to define the level of fidelity in virtual reality simulation. Surg Endosc. Vol. 20, pp. 1368-1375.

Latifi, R. et al., (2004). Telepresence and telemedicine in trauma and emergency care management. Stud. Health Technol. Inform., Vol. 104, pp. 193-199.

Lemole G.M. Jr et al., (2007). Virtual reality in neurosurgical education: part-task ventriculostomy simulation with dynamic visual and haptic feedback. Neurosurgery Vol. 61, pp. 142-149.

Montgomery K, et al., (2005). User interface paradigms for patient-specific surgical planning: lessons learned over a decade of research. Comput Med Imaging Graph. Vol. 29, pp. 203-222.

O'Neill, S.K. et al., (2000). The design and implementation of an off-the-shelf, standardsbased tele-ultrasound system. I Telemed. Telecare, Vol. 6, suppl 2, pp. 52-53.

Pande, R.U. et al., (2003). The telecommunication revolution in the medical field: present applications and future perspective. Curr. Surg., Vol. 60, pp. 636-640.

Rheuban, K.S. \& Sullivan, E. (2005). The University of Virginia Telemedicine Program: traversing barriers beyond geography. I Long-Term Eff. Med. Implants, Vol. 15, pp. 49-56.

Sable, C. (2002). Digital echocardiography and telemedicine applications in pediatric cardiology. Pediatr-Cardiol. Vol. 23, pp. 358-369.

Schlag, P.M. et al., (1999). Telemedicine - The New Must for Surgery. Archives of Surgery Vol. 134, pp. 1216-1221.

Smith, A.C. et al., (2004). Diagnostic accuracy of and patient satisfaction with telemedicine for the follow-up of paediatric burns patients. If Telemed. Telecare, Vol. 10, pp. 193198.

Testi D., et al., (2006). Efficacy of stereoscopic visualization and six degrees of freedom interaction in preoperative planning of total hip replacement. Med Inform Internet Med. Vol. 31, pp. 205-218. 
van Bergen P. et al., (2000) The effect of high-definition imaging on surgical task efficiency in minimally invasive surgery: an experimental comparison between threedimensional imaging and direct vision through a stereoscopic TEM rectoscope. Surg Endosc., Vol. 14, pp. 71-74.

Wootton, R. et al., (2005). E-health and the Universitas 21 organization: 2. Telemedicine and underserved populations. el Telemed. Telecare, Vol. 11, pp. 221-224. 


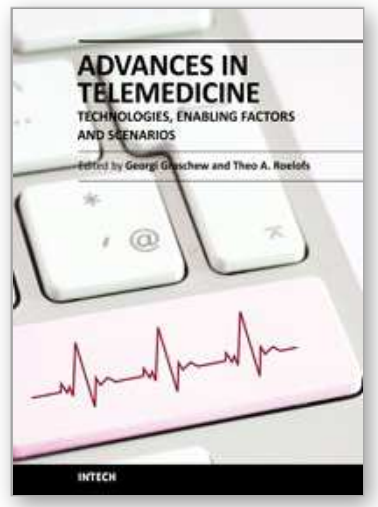

\author{
Advances in Telemedicine: Technologies, Enabling Factors and \\ Scenarios \\ Edited by Prof. Georgi Graschew
}

ISBN 978-953-307-159-6

Hard cover, 412 pages

Publisher InTech

Published online 16, March, 2011

Published in print edition March, 2011

Innovative developments in information and communication technologies (ICT) irrevocably change our lives and enable new possibilities for society. Telemedicine, which can be defined as novel ICT-enabled medical services that help to overcome classical barriers in space and time, definitely profits from this trend. Through Telemedicine patients can access medical expertise that may not be available at the patient's site.

Telemedicine services can range from simply sending a fax message to a colleague to the use of broadband networks with multimodal video- and data streaming for second opinioning as well as medical telepresence. Telemedicine is more and more evolving into a multidisciplinary approach. This book project "Advances in Telemedicine" has been conceived to reflect this broad view and therefore has been split into two volumes, each covering specific themes: Volume 1: Technologies, Enabling Factors and Scenarios; Volume 2: Applications in Various Medical Disciplines and Geographical Regions. The current Volume 1 is structured into the following thematic sections: Fundamental Technologies; Applied Technologies; Enabling Factors; Scenarios.

\title{
How to reference
}

In order to correctly reference this scholarly work, feel free to copy and paste the following:

Georgi Graschew, Theo A. Roelofs, Stefan Rakowsky and Peter M. Schlag (2011). Real-time Interactive Telemedicine for Ubiquitous Healthcare: Networks, Services and Scenarios, Advances in Telemedicine: Technologies, Enabling Factors and Scenarios, Prof. Georgi Graschew (Ed.), ISBN: 978-953-307-159-6, InTech, Available from: http://www.intechopen.com/books/advances-in-telemedicine-technologies-enablingfactors-and-scenarios/real-time-interactive-telemedicine-for-ubiquitous-healthcare-networks-services-andscenarios

\section{INTECH}

open science | open minds

\author{
InTech Europe \\ University Campus STeP Ri \\ Slavka Krautzeka 83/A \\ 51000 Rijeka, Croatia \\ Phone: +385 (51) 770447 \\ Fax: +385 (51) 686166 \\ www.intechopen.com
}

\author{
InTech China \\ Unit 405, Office Block, Hotel Equatorial Shanghai \\ No.65, Yan An Road (West), Shanghai, 200040, China \\ 中国上海市延安西路65号上海国际贵都大饭店办公楼 405 单元 \\ Phone: +86-21-62489820 \\ Fax: +86-21-62489821
}


(C) 2011 The Author(s). Licensee IntechOpen. This chapter is distributed under the terms of the Creative Commons Attribution-NonCommercialShareAlike-3.0 License, which permits use, distribution and reproduction for non-commercial purposes, provided the original is properly cited and derivative works building on this content are distributed under the same license. 